\title{
Positive Wassermann-Reaktion.
}

Bémerkungen zu dem Aufsatz des Prof. E. H of $\mathbf{f} \operatorname{man} \mathbf{n}$ in Nr. 22 dieser Wochenschrift.

Von Dr. F. Halla in Wien.

Ein Arzt hatte als Student ein unangenehmes Erlebnis, das gleichfalls zeigen soll, wie vorsichtig man eine einmalige positive WaR. bewerten soll. Im Alter von 20 Jahren begab er sich auf die Wiener Klinik Fing e r, um dort an sich eine Phimosenoperation vornehmen zu lassen. Er wurde angewiesen, nach der Ambulanz auf den betreffenden Assistenten mit anderen Patienten zu warten. Plötzlich befahl sie alle eine energische Schwester zur Blutuntersuchung. In der Meinung, daß grundsätzlich dort alle Patienten derart untersucht werden, widersetzte er sich gar nicht. Bei seinem Wiederkommen teilte man ihm aus dem Protokoll mit, daß̧ er eine positive Reaktion aufweise. Er war dem Selbstmord nahe. Dabei war er sonderbar überrascht. Hatte er doch noch keinen einzigen Koitus hinter sich, hatte früher nichts als eine vorübergehende leichte Balanitis und wußte er auch, daß sowohl seine Eltern, wie Großeltern, alle langlebig und völlig gesund waren und sie alle keinerlei syphilitische Zeichen aufwiesen. Er ließ sich sofort privat untersuchen. Hierbei fiel die Probe ganz negativ aus. Dann verlangte er auf der Klinik (deren Wassermann-Station internationalen Ruf genoß) eine nochmalige Untersuchung und wieder das gleiche negative Resultat. In gleicher Weise fielen die späteren, im Laufe der Jahre durchgeführten Proben aus Es läßt sich denken, welche Folgen ein solcher Befund bei noch sensibleren Personen, bzw. bei Bekanntwerden in der Familie usw. auslösen kann, wenn beachtet wird, daß er selbst nachher jahrelang unter schweren Depressionen litt. 